\title{
A Simple Electrochemical Approach for Determination and Direct Monitoring of Drug Degradation in Water
}

\author{
M.TAHIR SOOMRO' ${ }^{*}$, IQBAL M. I. ISMAIL ${ }^{1,2}$, \\ ABDUL HAMEED ${ }^{1}$ and MOHAMMAD ASLAM ${ }^{1}$ \\ ${ }^{1}$ Center of Excellence in Environmental Studies, King Abdulaziz University, \\ P.O. Box 80216, Jeddah 21589, (Saudi Arabia). \\ ${ }^{2}$ Chemistry Department, Faculty of Science, King Abdulaziz University, \\ P.O. Box 80203, Jeddah 21589, (Saudi Arabia). \\ http://dx.doi.org/10.12944/CWE.8.3.05
}

(Received: July 23, 2013; Accepted: August 27, 2013)

\begin{abstract}
The application of electrochemical techniques for the determination of pharmaceutical drugs in water is reported here. The experiment is designed for use in undergraduate chemistry courses. Two most commonly used pharmaceutical drugs e.g., ibuprofen (IBP) and paracetamol (PCM) were investigated for their identification and electrochemical investigations using cyclic votlammetry $(\mathrm{CV})$ and square wave (SQW) voltammetry. The major objective of this communication is to enable students to get familiar and use sophisticated electrochemical techniques. A detailed protocol for the detection of IBP and PCM is presented in this work. The developed protocol was used to study sunlight photocatalytic degradation of IBP and PCM in photocatalytic degradation experiments carried out in the presence of $\mathrm{ZnO}$ based photocatalyst. This easy and efficient approach can easily be included in undergraduate chemistry courses.
\end{abstract}

Keywords: Pharmaceutical Drug, Ibuprofen, Paracetamol, Wastewater, Cyclic Voltammetry, Square Wave Voltammetry, Determination, Degradation .

\section{INTRODUCTION}

Most pharmaceuticals are persistent in wastewater especially the effluent from pharmaceutical industries and also from hospital wastes. Considerable attention has been already devoted for the removal of these pharmaceuticals from wastewater. Ibuprofen (IBP) and paracetamol (PCM) are two important pharmaceutical drugs which are regularly used to cure from fever, migraine, and diseases resulted from inflammatory disorder ${ }^{1-4}$. Fig 1 shows the chemical structure of IBP and PCM.<smiles>CC(C)Cc1ccc(C(C)C(=O)O)cc1</smiles>

Ibuprofen<smiles>CC(=O)Nc1ccc(C)cc1</smiles>

Paracetamol
It is reported that presence of IBP and PCM and their metabolites in wastewater have adverse effects on environment due to the ecotoxicity potential and their exposure could also be very harmful to human health ${ }^{5,6}$. Therefore their detection and removal from wastewater play vital role in wastewater treatment methodologies.

Several methods have been described in literature regarding detection of IBP and PCM using conventional or novel techniques. Such techniques include spectrophotometry, spectrofluorimetry, GCMS, HPLC, electrophoresis and etc ${ }^{1-4,7-12}$. In addition electrochemical techniques are also widely use for determination of IBP and PCM in wastewater ${ }^{12,13}$. But unexpectedly only limited number of reports are found in literature illustrating the methods for removal of IBP and PCM from wastewater ${ }^{5,6}$.

Fig.1: Structure of IBP and PCM. 
In the present work students are introduced to the electrochemical detection of IBP and $\mathrm{PCM}$ in water. Instrumentation for electrochemical measurements as compared with other available techniques is cost effective, simple and easy to handle. Sensitivity and fast analysis are additional advantages.

Cyclic voltammetry is one of the very versatile and most regularly used electrochemical technique in fundamental research. On the other hand square wave (SQW) voltammetry affords high sensitivity with fast analysis time and this is because of zero background charging current. An excellent material for supplementary reading is suggested to acquire necessary understanding of $C V$ and SQW voltammetry ${ }^{14-20}$. Both, CV and SQW voltammetry were employed to examine IBP and PCM in water.

The sunlight photocatalytic environmental remediation is regarded as the cheap and clean alternative of currently expensive technologies as it leads to the complete mineralization of pollutants essentially in water purification ${ }^{21-23}$. Using cyclic voltammetry the sunlight photocatalytic degradation of pharmaceutical drugs were also studied. The method is novel and provide us opportunity to observe the complete mineralization of IBP and PCM present in wastewater. Using cyclic voltammetry the information of degradation product and mechanism of degradation, as a result of photocatalytic degradation, is also obtained.

The work is purposefully designed to develop a easy protocol for determination and removal of pharmaceuticals drugs present in wastewater using electrochemistry.

\section{EXPERIMENTAL}

\section{Reagents and Solutions}

Ibuprofen (IBP) and paracetamol (PCM) tablets were purchased from local market in Jeddah, Kingdom of Saudi Arabia. Before cyclic voltammetric measurements IBP and PCM were purified by means of re-crystallization procedure. 5-10 g of IBP tablet was taken and grinded using pestle and mortar. A fine powder obtained was further added in $60-80 \mathrm{~mL}$ of acetone in $100 \mathrm{~mL}$ beaker. After that a continuous stirring was carried out using glass rod for approximately 10-20 minutes so that maximum amount of IBP dissolve in acetone. Then the mixture was filtered and acetone evaporated on hot plate at $40{ }^{\circ} \mathrm{C}$ until thick liquid obtained. Finally the beaker was kept in vacuum oven for 2-3 hours to obtain purified crystals of IBP. For purification of PCM followed the same procedure.

Potassium chloride (BDH), potassium ferricyanide (HiMedia), sodium acetate (Sigma), and acetic acid (Sigma) were used as received from the supplier without further purification.

Milli-Q water was used throughout the study for making sample solutions. Stock solutions of 100 ppm of IBP and PCM were made in ethanol and used for further dilution using acetate buffer. All solutions were made in acetate buffer of $\mathrm{pH} 4.7$ and concentration $0.25 \mathrm{M}$. All glassware were cleaned carefully, rinsed at least three times with double distilled water and oven dried at $100{ }^{\circ} \mathrm{C}$ before use.

$\mathrm{ZnNO}_{3}$ (HiMedia), $\mathrm{KOH}$ (Loba Chemie), and ammonium metavanadate $\left(\mathrm{NH}_{4} \mathrm{VO}_{3}\right.$, Loba Chemie) were purchased for synthesis of $\mathrm{ZnO}$ based photocatalyts. The $\mathrm{ZnO}$ based vanadium impregnated photocatalyst was synthesized by wet impregnation techniques using ammonium metavanadate as precursors for $\mathrm{V}^{6+}$ ions. The $\mathrm{ZnO}$ used in the preparation of impregnated catalyst was synthesized by hydrolyzing Zinc nitrate solution by $\mathrm{KOH}$. The hydrated gel after filtration and drying was calcined at $500^{\circ} \mathrm{C}$ in muffle furnace. After impregnation the impregnated catalyst was again calcined for optimum surface geometry.

\section{Apparatus and Procedure}

A VSP multi-channel potentiostat (Biologic Science Instrument, USA) provided with Ec-lab Software was used for carrying out all voltammetric measurements. A Glassy carbon (GC) working electrode with a diameter of $3 \mathrm{~mm}$, a platinum $(\mathrm{Pt})$ counter electrode, and $\mathrm{a} \mathrm{Ag} / \mathrm{AgCl}$ reference electrode were purchased (Biologic Science Instrument) and used as received. The electrochemical cell of maximum capacity of 10-20 $\mathrm{mL}$ equipped with gas bubbler and gas outlet 
assembly was used. All voltammetric measurements was accomplished using usual procedure such as by immersing working, counter and reference electrodes in an electrochemical cell. All experiments were performed at ambient temperature. The $30 \mathrm{ppm}$ sample solutions of IBP and PCM were tested for their identification. Variable scan rate from $10-500 \mathrm{mV} / \mathrm{s}$ was employed using cyclic voltammetry. The square wave voltammetric parameters are as follows: pulse height $25 \mathrm{mV}$, pulse width $50 \mathrm{~ms}$, and step height $10 \mathrm{mV}$. All cyclic voltammograms presented were recorded against $\mathrm{Ag} / \mathrm{AgCl}$ reference electrode and all potential values are in volts vs. $\mathrm{Ag} / \mathrm{AgCl}$ reference electrode.

The working electrode was pretreated (activated) by performing 10 cycles in $0.1 \mathrm{M} \mathrm{H}_{2} \mathrm{SO}_{4}$ between $0 \mathrm{~V}$ to $2 \mathrm{~V}$ at $100 \mathrm{mV} / \mathrm{s}$. The working electrode surface was cleaned first using diamond paste and then with alumina paste by manual procedure. After that the polished electrode was rinsed with double distilled water and immersed in $5 \% \mathrm{HNO}_{3}$ solution for 5 second then rinsed again with double distilled water and air dried before use. No deterioration of working electrode was detected during voltammetric measurements. The background current was also measured in absence of pharmaceutical drugs in acetate buffer.

\section{Sunlight Photocatalytic Degradation}

To study the photocatalytic degradation 50 ppm solution of IBP in simple Milli-Q water was used. $100 \mathrm{mg}$ vanadium impregnated $\mathrm{ZnO}$ powder was added in $100 \mathrm{~mL}$ solution of IBP and stirred for 30 minutes to get the homogenous dispersion. After that the solution was exposed to sunlight. For cyclic voltammmetric measurements $10 \mathrm{~mL}$ of IBP was taken at different period of time and diluted using acetate buffer and Milli-Q water. The photocatalytic degradation of PCM was also studied followed the above mentioned procedure.

\section{RESULTS AND DISCUSSION}

\section{Voltammeric Response at Bare Glassy Carbon Electrode}

Fig 2 shows the characteristic cyclic voltammogram of IBP recorded at bare glassy

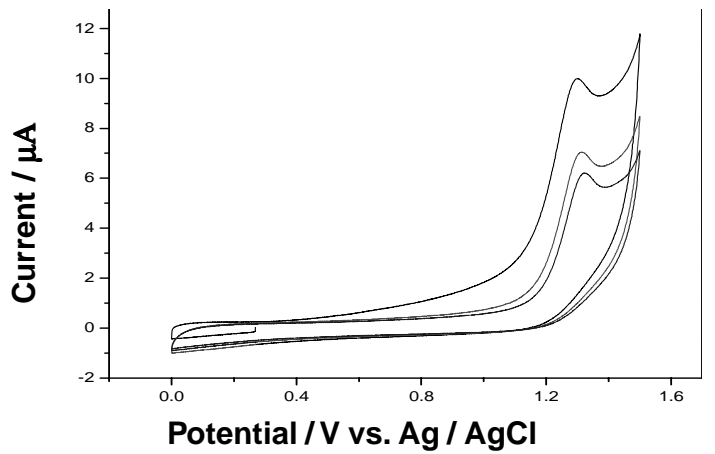

Fig. 2: Cyclic Voltammograms of $30 \mathrm{ppm}$ IBP in $0.25 \mathrm{M}$ acetate buffer of $\mathrm{pH} 4.7$ at sweep rate of $100 \mathrm{mV} / \mathrm{s}$ with number of repeated scan, $n=3$.

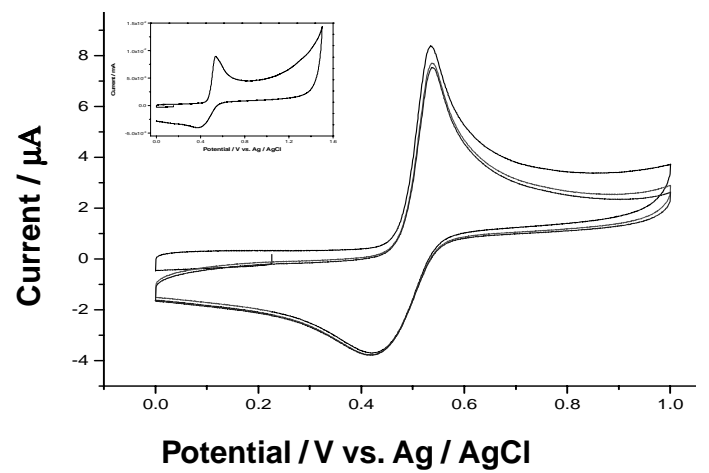

Fig. 3: Cyclic Voltammograms of $30 \mathrm{ppm}$ PCM in $0.25 \mathrm{M}$ acetate buffer of $\mathrm{pH} 4.7$ at scan rate of $100 \mathrm{mV} / \mathrm{s}$ with number of repeated scan, $n=3$. An inset graph showing cyclic voltammogram of PCM scanned between $0 \mathrm{~V}$ to $+1.5 \mathrm{~V}$ vs. $\mathrm{Ag} / \mathrm{AgCl}$.

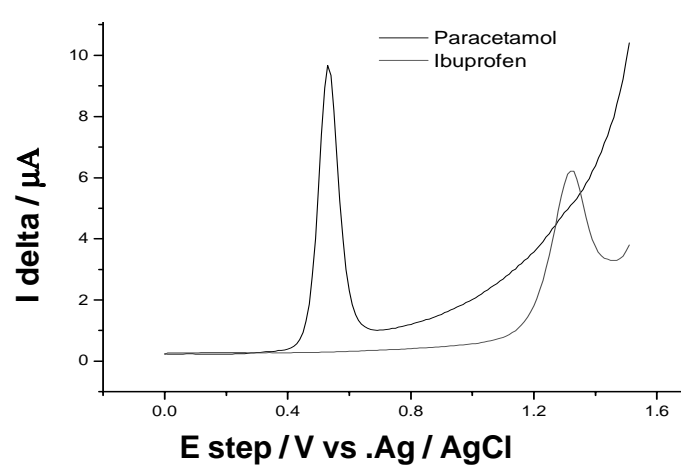

Fig. 4: Square-wave Voltammograms of $30 \mathrm{ppm}$ IBP (red) and 30 ppm PCM (black) in $0.25 \mathrm{M}$ acetate buffer of $\mathrm{pH}$ 4.7. The square wave voltammetric parameters are: pulse height 25 $\mathrm{mV}$, pulse width $50 \mathrm{~ms}$, and step height $10 \mathrm{mV}$. 
carbon electrode. The applied potential range was $0 \mathrm{~V}$ to $+1.5 \mathrm{~V}$ vs. $\mathrm{Ag} / \mathrm{AgCl}$ reference electrode. An irreversible oxidation peak was observed for IBP at around $+1.29 \mathrm{~V}$ during a forward scan.

The absence of reduction peak on the reverse scan indicating that the formation of highly reactive intermediate product upon oxidation which reacted either with solvent or dimerized quickly into a dimer. The electrochemical oxidation of IBP fits into an EC reaction that is electron transfer reaction followed by homogeneous chemical reaction.

$$
\begin{aligned}
& \mathrm{A}-\mathrm{e}=\mathrm{B} \\
& \mathrm{B} \rightarrow \text { Product }
\end{aligned}
$$

The characteristic cyclic voltammogram obtained for PCM is represented in figure 3. To obtain a well defined peak the potential was scanned between $0 \mathrm{~V}$ to $+1 \mathrm{~V}$. An inset graph in figure 3 also recorded for the potential range of $0 \mathrm{~V}$ to $+1.5 \mathrm{~V}$ just to confirm that there is no other peak for PCM. The cyclic voltammogram of PCM is interpreted as quasi reversible process, with " $\Delta \mathrm{E} \geq$ " $100 \mathrm{mV} / \mathrm{n}$, coupled with a slow chemical reaction i.e., an EC reaction.

Electrochemically well defined response depends on many factors and some of them are electrode material, supporting electrolyte, and solvent decomposition potentials (i.e., potential window). Because water oxidize itself when potential applied further than $+1.23 \mathrm{~V}$ and due to this water decomposition background current the working range (potential) is restricted to $+1.5 \mathrm{~V}$ when using glassy carbon as working electrode. So beyond $+1.5 \mathrm{~V}$ the oxidation or reduction peak, if any, is obscured.

From the cyclic voltammograms of IBP and PCM one can also deduce that the oxidation of PCM is easier than IBP. The potential difference in peak position is found to be $800 \mathrm{mV}$ which allows easy identification of IBP and PCM in same solution. Overlapped square wave (SQW) voltammograms over one another are shown in figure 4 obtained for IBP and PCM. Square wave voltammogram for a mixture of IBP and PCM was also recorded and is shown in figure 5. As expected the peaks of IBP and PCM are clearly resolved and identified without

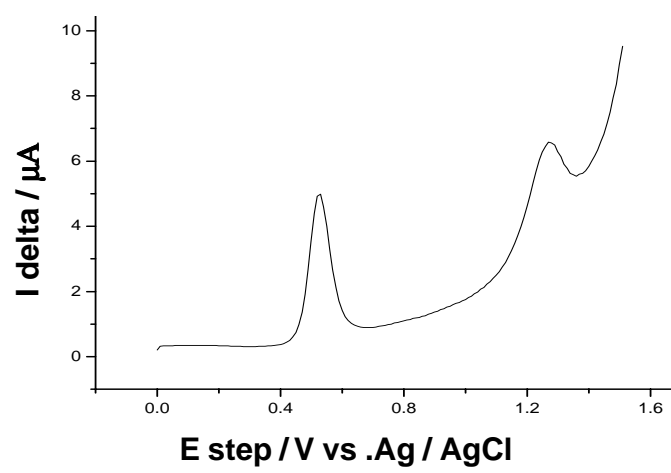

Fig. 5: Square wave voltammograms of mixture of IBP and PCM in $0.25 \mathrm{M}$ acetate buffer of $\mathrm{pH}$ 4.7. The square wave voltammetric parameters are: pulse height $25 \mathrm{mV}$, pulse width $50 \mathrm{~ms}$, and step height $10 \mathrm{mV}$.

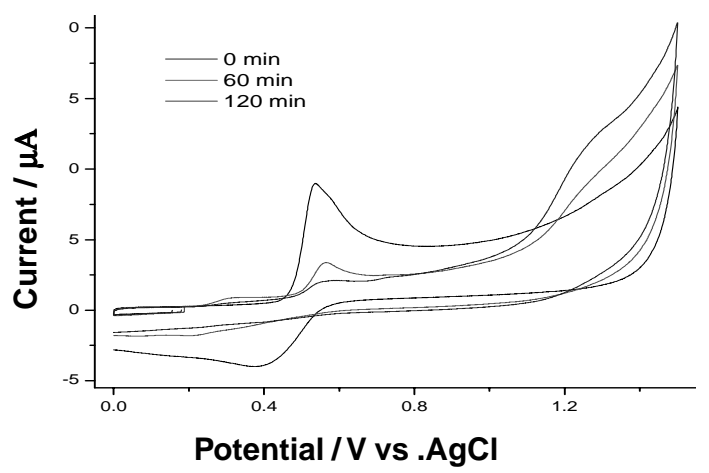

Fig. 6: Cyclic voltammetric study of sunlight photocatalytic degradation of $30 \mathrm{ppm}$ IBP in water. The cyclic voltammogram was taken in $0.25 \mathrm{M}$ acetate buffer of $\mathrm{pH}$ 4.7.

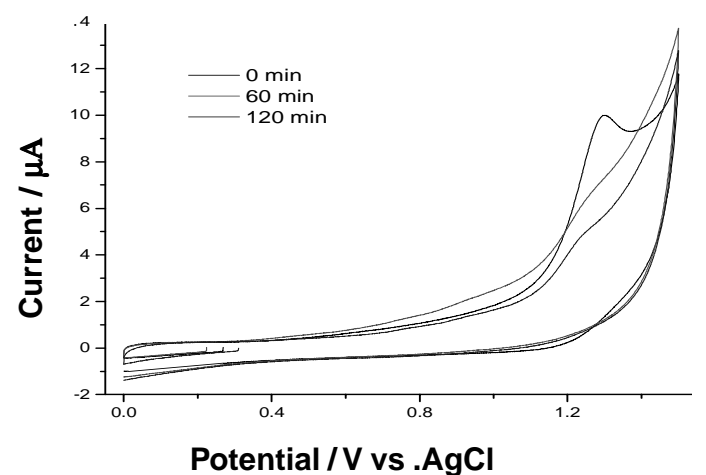

Fig. 7: Cyclic voltammetric study of sunlight photocatalytic degradation of $30 \mathrm{ppm}$ PCM in water. The Cyclic voltammogram was taken in $0.25 \mathrm{M}$ acetate buffer of $\mathrm{pH}$ 4.7. 
any problem and letting us analysis of mixture from wastewater. To obtain a well define square wave voltammogram optimization studies were also done. The optimal values of square wave voltammetric parameters were obtained and are as follows: pulse height $25 \mathrm{mV}$, pulse width $50 \mathrm{~ms}$, and step height $10 \mathrm{mV}$. All square wave voltammograms were recorded using such parameters.

\section{Voltammetric Study of Sunlight Photocatalytic Degradation in water}

Sunlight photocatalytic degradation offers a new alternative against persistent organic pollutants present in wastewater. During the CV analysis of the degradation products in the photocatalytic degradation studies it was observed that $\mathrm{CV}$ is a powerful alternative of other analytical techniques such as UV-Visible spectroscopy and HPLC for monitoring the degradation products. The sunlight photocatalytic degradation of IBP and PCM are shown in figure 6 and figure 7 . The studies were carried out in different time intervals. The complete degradation and/or mineralization of IBP and PCM were observed in about one hour. No side products or metabolites were detected in cyclic voltammetric investigations. The complete mineralization of pharmaceutical drugs into inorganic ions also evidenced from the increase of the background current in cyclic voltammograms of IBP and PCM.

\section{CONCLUSION}

The protocol demonstrated above is successfully applied for the determination of IBP and PCM in water using cyclic voltammetry and SQW voltammetry. Sunlight photocatalytic degradation study of IBP and PCM was also carried out using cyclic voltammetry. Cyclic voltammetry is very useful for identification of pharmaceutical drugs. On the other hand for quantitation square wave voltammetry is more superior than $\mathrm{CV}$ and can be easily used for that purpose. The developed protocol gives students an understanding about electrochemical instrumentation used for pharmaceutical drug determination in wastewater. In addition, students also learned about novel method for removal of pharmaceutical drug from wastewater. As a result students received experience in both electrochemistry and method development.

\section{ACKNOWLEDGMENT}

For carrying out the work the Ministry of Higher Education (MOHE) and King Abdulaziz University (DSR) are highly appreciated for their technical and financial support.

\section{REFERENCES}

1. Miner D. J., Rice J. R., Riggin R. M. and Kissinger P.T., Analytical Chemistry, 53, 2258 (1981).

2. Motoc S., Manea F., Pop A., Pode R. and Burtica G., Advanced Science, Engineering and Medicine, 3, 7 (2011).

3. Hamoudová R. and Pospíšilová M., Journal of Pharmaceutical and Biomedical Analysis, 41, 1463 (2006).

4. Wangfuengkanagul N. and Chailapakul O., Journal of Pharmaceutical and Biomedical Analysis, 28, 841 (2002).

5. Escher B. I., Baumgartner R., Koller M., Treyer K., Lienert J. and McArdell C. S., Water Research, 45, 75 (2011).

6. Ort C., Lawrence M. G., Reungoat J., Eaglesham G., Carter S. and Keller J., Water
Research, 44, 605 (2010).

7. Kachoosangi R. T., Wildgoose G. G. and Compton R. G., Analytica Chimica Acta, 618, 54 (2008).

8. Ghoneim E. M. and El-Desoky H. S., Bioelectrochemistry, 79, 241 (2010).

9. Whelan M. R., Ford J. L. and Powell M. W., $J$ Pharm Biomed Anal, 30, 1355 (2002).

10. Khoshayand M. R., Abdollahi H., Shariatpanahi M., Saadatfard A. and Mohammadi A., Spectrochimica Acta Part A: Molecular and Biomolecular Spectroscopy, 70, 491 (2008).

11. Ternes T. A., Trends in Analytical Chemistry, 20, 419 (2001).

12. Manea F., Motoc S., Pop A., Remes A. and Schoonman J., Nanoscale Research 
Letters, 7, 331 (2012).

13. Stefan-van Staden R.-I., Mashile T., Mathabathe K. C. and van Staden J. F., Instrumentation Science \& Technology, 37, 197 (2009).

14. Chen A. and Shah B., Analytical Methods, 5, 2158 (2013).

15. Bard A. and Faulkner L., Electrochemical methods: fundamentals and applications, Wiley (2001).

16. Heinze J., Angewandte Chemie International Edition in English, 23, 831 (1984).

17. Kissinger P. T. and Heineman W. R., Journal of Chemical Education, 60, 702 (1983).
18. Mabbott G. A., Journal of Chemical Education, 60, 697 (1983).

19. Krause M. S. and Ramaley L., Analytical Chemistry, 41, 1365 (1969).

20. Wang J., Bollo S., Lopez Paz J. L., Sahlin E. and Mukherjee B., Analytical Chemistry, 71, 1910 (1999).

21. Hameed A., Montini T., Gombac V. and Fornasiero P., Photochemical \& Photobiological Sciences, 8, 677 (2009).

22. Fatin S., Lim H., Tan W. and Huang N., Int. J. Electrochem. Sci, 7, 9074 (2012).

23. Reddy S., Kumara Swamy B. E., Vasan H. N. and Jayadevappa H., Analytical Methods, 4, 2778 (2012). 